\title{
Percutaneous pulmonary valve implantation after Ross-Konno aortoventriculoplasty: A cautionary word
}

\author{
Syed Murfad Peer, MD, and Pranava Sinha, MD, Washington, DC
}

Transcatheter pulmonary valve (TPV) placement was first reported in $2000^{1}$ and in 2010 received U.S. Food and Drug Administration approval for the percutaneous treatment of right ventricle (RV)-pulmonary artery (PA) conduit dysfunction. Although TPV placement carries acceptable morbidity and mortality, ${ }^{2}$ appropriate patient selection criteria are still evolving, especially for patients with major surgical anatomic remodeling.

We report a case of TPV implantation leading to distortion of the neoaortic root and coronary compression, with erosion into the aortic root leading to an iatrogenic aortopulmonary window in a patient who had previously undergone a Ross-Konno aortoventriculoplasty.

\section{CLINICAL SUMMARY}

An 11-year-old patient was seen with moderate mixed RV outflow tract (RVOT) conduit disease. He had

From the Department of Cardiovascular Surgery, Children's National Medical Center, Washington, DC.

Disclosures: Authors have nothing to disclose with regard to commercial support.

Received for publication Dec 17, 2013; revisions received Feb 6, 2014; accepted for publication Feb 10, 2014; available ahead of print March 20, 2014.

Address for reprints: Pranava Sinha, MD, Department of Cardiovascular Surgery, 111 Michigan Ave NW, Washington, DC 20010 (E-mail: psinha@childrensnational. org).

J Thorac Cardiovasc Surg 2014;147:e74-5

0022-5223/\$36.00

Copyright (C) 2014 by The American Association for Thoracic Surgery

http://dx.doi.org/10.1016/j.jtcvs.2014.02.032 undergone interrupted aortic arch repair as a neonate, followed by Ross-Konno aortoventriculoplasty and RVOT reconstruction with a $19-\mathrm{mm}$ pulmonary homograft at 3 years of age.

Suitability of TPV implantation was assessed with standard simultaneous balloon inflation in the RVOT and coronary angiograms to rule out left coronary artery compression. After pre-stenting of the conduit with a P3110 Palmaz XL (Cordis Corporation, Miami, Fla), a Melody percutaneous valve (Medtronic, Inc, Mounds View, Minn) mounted on an 18-mm Symphony delivery system (Medtronic) was implanted. The TPV was postdilated to a final diameter of $20 \mathrm{~mm}$ with an Atlas balloon (Bard Peripheral Vascular, Tempe, Ariz).

On postprocedure day 1 , transthoracic echocardiography revealed mild neoaortic valve insufficiency. This progressed to moderate insufficiency on follow-up 10 days later.

Repeated cardiac catheterization demonstrated lateral compression of the neoaortic root, and left main coronary artery (LMCA) compression. There was moderate aortic insufficiency and markedly elevated left ventricular end-diastolic pressure. An ascending aorta-PA fistula was also noted (Figure 1). During the procedure, the patient had a cardiac arrest necessitating institution of extracorporeal membrane oxygenation support and was taken for emergency surgery.

Intraoperatively, it was noted that the TPV had eroded through the conduit into the neoaortic root and ascending
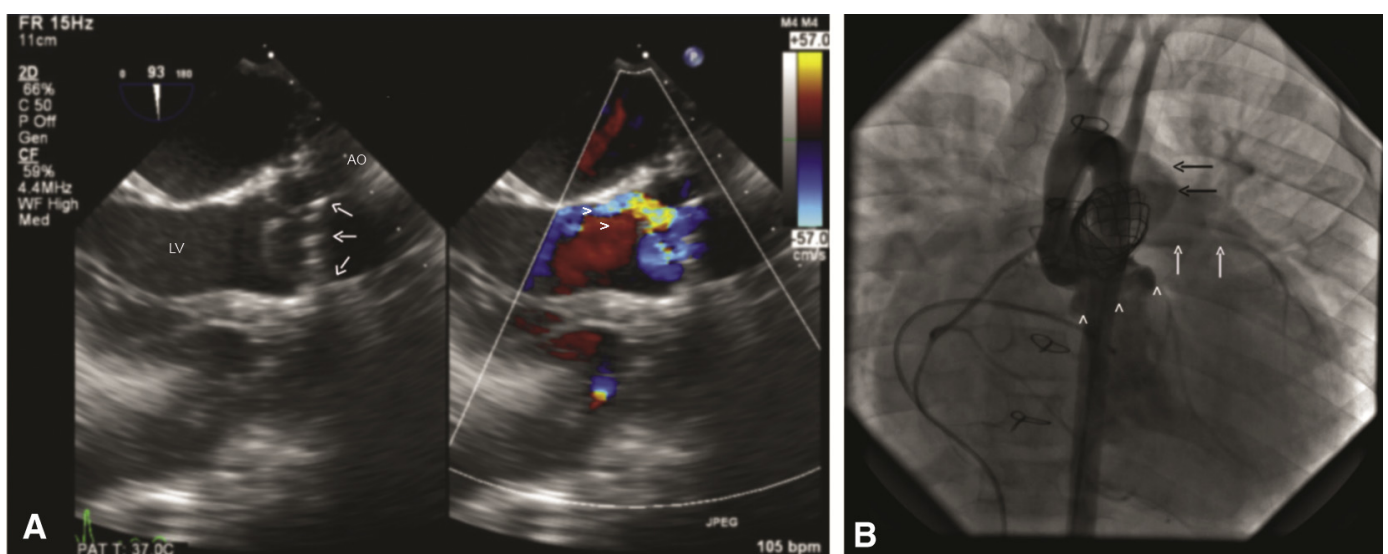

FIGURE 1. Preoperative images after transcatheter pulmonary valve implantation. A, Transesophageal echocardiogram in midesophageal long-axis view showing distortion of the neoaortic root by the stented transcatheter pulmonary valve (arrows) and moderate aortic insufficiency (arrowheads). B, Aortogram in anteroposterior view demonstrates compression from the transcatheter pulmonary valve causing moderate aortic insufficiency (arrowheads) and decreased flow in the left coronary artery (white arrows) and opacification of the pulmonary artery (black arrows). Ao, Ascending aorta; $L V$, left ventricle. 


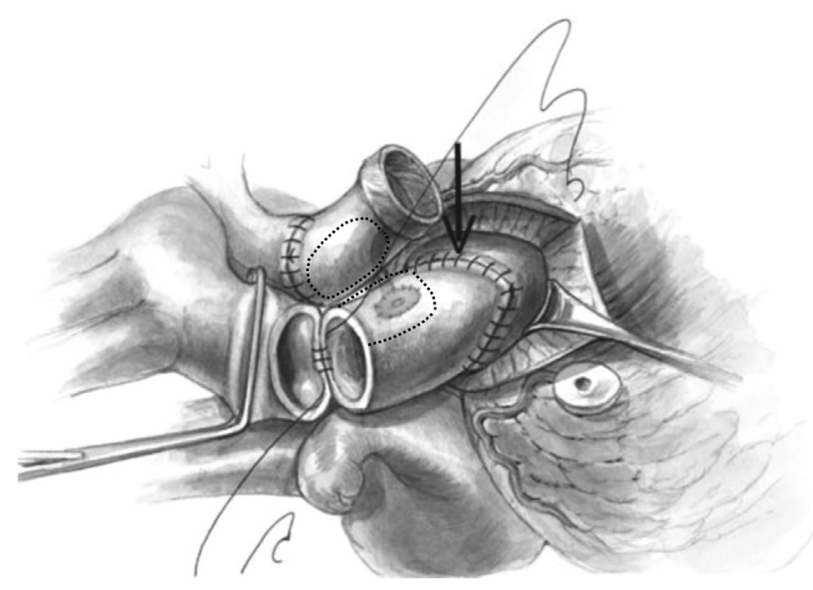

FIGURE 2. Ross-Konno aortoventriculoplasty leads to anterior displacement of the neoaortic root in relation to the right ventricular outflow tract. A stented transcatheter pulmonary valve in the right ventricular outflow tract would directly compress the neoaortic root (arrow). The margins of the aortopulmonary fistula are indicated with a dotted line. Modified with permission from Jonas RA. Left ventricular outflow tract obstruction: aortic valve stenosis, subaortic stenosis, supravalvular aortic stenosis. In: Jonas RA, editor. Comprehensive surgical management of congenital heart disease. London: Hodder Arnold; 2004:320-40.

aorta, creating a $2 \times 3$-cm defect extending from just above the LMCA ostium to the mid ascending aorta, with distortion of the LMCA ostium. The neoaortic leaflets and the LMCA ostium were intact.

The defect in the aorta was repaired with an expanded polytetrafluoroethylene (W. L. Gore \& Associates, Inc, Flagstaff, Ariz) patch. The RV-PA conduit was replaced with a 24-mm pulmonary homograft, and the patient was successfully weaned from cardiopulmonary bypass without any difficulty.

Follow-up echocardiography demonstrated mild to moderate left ventricular dysfunction, trivial aortic insufficiency and a normally functioning RV-PA conduit.

\section{DISCUSSION}

Left coronary artery compression by TPV is a risk in certain anatomic subsets of patients, ${ }^{3}$ including patients who have previously undergone the Ross procedure. ${ }^{2,3}$ Compression of the aortic root by a TPV implant with erosion of the Melody valve into the adjacent ascending aorta has not previously been reported.

The Ross-Konno aortoventriculoplasty requires the native aortic annulus to be incised and enlarged with a septal augmenting patch and leads to anterior displacement of the neoaorta into the right ventricular infundibulum, distorting the RVOT architecture. Coronary orientation may also be altered by reimplantation into the larger neoaorta. Implantation of a TPV into the RVOT consequently will result in a significantly greater risk of compression of the neoaortic root, lateral erosive pressure on the autograft, and potential proximal coronary artery compression (Figure 2). The integrity of the pulmonary autograft is also questionably inferior to a normal aortic root, as evidenced by late reoperations for autograft dilation in the Ross population ${ }^{4}$ as well as histologic analysis. ${ }^{5}$ This may make the autograft tissue more prone to damage or erosion from extrinsic compression from a metallic stent-based valve, as seen in this case.

Careful preimplantation consideration of the position and course of the coronary artery branches has been a mainstay in the evaluation for TPV; however, the predictive value of preimplant angiography may not be sufficient to predict failure in patients with substantially altered postsurgical anatomy of the aortic root and RVOT, as demonstrated by this case.

After a Ross-Konno aortoventriculoplasty, evaluation of suitability for TPV should consider not only the absence of coronary compression by angiography and echocardiograms but also meticulous 3-dimensional assessment of the spatial relationships between the RVOT and the aortic root.

\section{CONCLUSIONS}

Geometry of the RVOT and its relation to the reconstructed aortic root is altered after Ross-Konno aortoventriculoplasty and should be carefully evaluated before TPV replacement in these patients.

\section{References}

1. Bonhoeffer P, Boudjemline Y, Saliba Z, Merckx J, Aggoun Y, Bonnet D, et al Percutaneous replacement of pulmonary valve in a right-ventricle to pulmonary-artery prosthetic conduit with valve dysfunction. Lancet. 2000;356: 1403-5

2. McElhinney DB, Hellenbrand WE, Zahn EM, Jones TK, Cheatham JP, Lock JE et al. Short- and medium-term outcomes after transcatheter pulmonary valve placement in the expanded multicenter US Melody valve trial. Circulation. 2010;122:507-16.

3. Zahn EM, Hellenbrand WE, Lock JE, McElhinney DB. Implantation of the Melody transcatheter pulmonary valve in patients with a dysfunctional right ventricular outflow tract conduit: early results from the U.S. clinical trial. J Am Coll Cardiol. 2009;54:1722-9.

4. Charitos EI, Takkenberg JJ, Hanke T, Gorski A, Botha C, Franke U, et al Reoperations on the pulmonary autograft and pulmonary homograft after the Ross procedure: an update on the German Dutch Ross Registry. J Thorac Cardiovasc Surg. 2012;144:813-23.

5. Rabkin-Aikawa E, Aikawa M, Farber M, Kratz JR, Garcia-Cardena G, Kouchoukos NT, et al. Clinical pulmonary autograft valves: pathologic evidence of adaptive remodeling in the aortic site. J Thorac Cardiovasc Surg. 2004;128: 552-61 